\title{
Energy Efficiency in Smart Grid: A Prospective Study on Energy Management Systems
}

\author{
Hermes José Loschi, Julio Leon, Yuzo Iano, Ernesto Ruppert Filho, Fabrizzio Daibert Conte, \\ Telmo Cardoso Lustosa, Priscila Oliveira Freitas \\ Department of Communications, Faculty of Electrical and Computer Engineering, University of Campinas \\ (UNICAMP), Campinas/SP, Brazil \\ Email: eng.hermes.loschi@ieee.org
}

Received 2 June 2015; accepted 28 August 2015; published 31 August 2015

Copyright (C) 2015 by authors and Scientific Research Publishing Inc.

This work is licensed under the Creative Commons Attribution International License (CC BY).

http://creativecommons.org/licenses/by/4.0/

(c) (i) Open Access

\begin{abstract}
The term Smart Grid has become a term to represent the benefits of a smart and sophisticated electrical grid, which can meet various social expectations related to sustainability and energy efficiency. The Smart Grid promises to enable a better power management for energy utilities and consumers, to provide the ability to integrate the power grid, to support the development of micro grids, and to involve citizens in energy management with higher levels of responsibility. However, this context comes with potential pitfalls, such as vulnerabilities to cyber-security and privacy risks. In this article, a prospective study about energy management, and exploring critical issues of modeling of energy management systems in a context Smart. Grid is presented along with background of energy management systems. An analysis of the demand response condition is also presented. Finally, the advantages and disadvantages of the implementation of energy management systems, and a comparison with the Brazilian electricity system are discussed.
\end{abstract}

\section{Keywords}

Smart Grid, Management, Cloud Computing, Energy, Efficiency

\section{Introduction}

Electric energy is essential to increase productivity and ensure a high quality of life; therefore, the relationship between electric power and economic growth is crucial. However, the consequence of the current worldwide economic growth and electricity demand is the depletion of energy resources. An essential and effective way to 
prevent the depletion of resources and promote economic growth at the same time is the application of the concept of energy efficiency through energy management systems, this is being the basic principle of the Smart Grid [1].

With the development of the Smart Grid, especially in the distribution grid, and with the possibility of load modeling, control over the peaks of energy demand becomes vital. The peaks of demand are serious problems and present themselves in the electrical system. The demand management in residential, commercial and industrial sectors can play an important role in reducing peak demand, reducing stress, overhead transmission and distribution lines. In many countries, there are various demand response programs, implemented for industrial and commercial loads [2].

There are few demand response (DR) programs in use for energy management in the residential sector. Direct load restriction is the most popular method used to reduce peak demand. However, when using direct control/restriction load, the consumer comfort can be compromised. In contrast, reduction of peak demand through load displacement can benefit consumers and energy utilities [2].

Peak demand of energy has caused adverse effects to the reliability and stability of the power system during recent decades. Reducing peak demand can reduce the risk of faults on transmission and distribution grid, consequently, the risk of interruptions. Demand response is one way to deal with peak events and avoid overload on the grid by providing the necessary flexibility through load displacement [2] [3].

Multiple energy management systems use the concepts of demand response; however, these DR systems are not broadly implemented due to complexity of the automation involved, particularly in industrial and commercial buildings. Although the residential sector is responsible for a significant amount of electrical energy demand, few DR programs are currently used in the residential field. Direct Load Control (DLC) is the method most used by energy utilities in Brazil to manage peak demand in the residential sector, where consumer loads are adjusted in time during peak network events [4] [5].

An energy management system that can automatically switch the operation of appliances during peak hours, can be used to management of peak demand without compromising the quality of supply to the consumer [6].

Up recognizing the very different perspectives and priorities of individuals and organizations involved in the electrical system, the authors propose a broad analysis through a prospective study to examine the different ways for the Smart Grid meeting the demands and developments of society. This study focuses on comparing the development of "Smart Grid" in different regions of the world and demonstrating the commitment of these countries to change the social and political contexts and expectations, which often are shaped by specific regions, goals and available resources.

\section{Smart Grid Technologies}

The term Smart Grid means more than a single technology or even a clear set of individual technologies. Is an "umbrella" term under which various technologies of electric power systems are considered, both in hardware and software. For some people, Smart Grid is characterized primarily as the addition of an information and communication technology (ICT), superimposed in a way on existing infrastructure. For others, Smart Grid represents the installation of new transmission lines, meters, and renewable energy generation [7].

However, in order for both conditions to comply, first it is necessary to understand the legacy electric systems worldwide. The current dominant infrastructure of electric power systems involves four basic elements:

- Generation: Electric power is generated in large-scale power plants;

- Transmission: High-voltage electrical energy is transported from the plant to substations closer to consumers;

- Distribution: Low voltage energy is distributed from substations to residences and commercial buildings;

- Consumer: Electricity used for consumer devices such as refrigerators, computers, lights, pumps and other devices used by residential, commercial, and industrial devices.

The main mechanism in power generation by current systems depends on the heat produced by burning fossil fuels, division of atoms in nuclear energy, or from the hydroelectric stations water movement. Except for solar cells, almost all other forms of power generation, including the burning of fossil fuels, nuclear, biomass, hydro, wind, concentrated solar, cogeneration, and need driving a turbine to produce electricity [7] [8].

The generation usually produces electricity with relatively low voltages ranging from 2 to 30 kilovolts $(\mathrm{kV})$, depending on the size of the unit. Since electricity is generated, its tension is amplified before transmission. A 
critical step between the generation of electricity and long-distance transmission involves a transformer to increase the voltage. Often, the generation of electric energy occurs far from the places where the electricity is needed, making the long distances of high voltage transmission lines, a crucial part of the electrical system. The long-distance transmission voltage varies from 115 to 120 kilovolts (KV), so the transformer plays a crucial role in increasing the voltage for transmission [7] [8].

The high-voltage transmission lines carry electricity from generating plants to local substations, where the energy is "left over" for a lower voltage and then sent through electric energy distribution networks for local users, including the industrial, commercial, and residential consumers. From the substation, the electrical energy is distributed locally within a community to individual buildings and houses. The voltage is usually reduced at the point of use, to the standard voltage of that region, which varies in different countries (with most consumers receiving 110 $120 \mathrm{~V}$ in the United States and 220 - $240 \mathrm{~V}$ in Europe) and with the requirements of electric power use [7] [8].

\section{Main Technologies}

The term Smart Grid represents the integration of digital technologies, sensors, and ICTs to empower and make the management on the use of electricity more reliable and efficient. Smart Grid includes technologies for the consumer (with which consumers interact) and the grid (transmission and distribution that are less visible to consumers). The Smart Grid technologies also include hardware and software [7] [8].

One of the definitions of the term Smart Grid is the integration of various technologies, products and services, from the generation, transmission, and distribution; using advanced communication and control technologies. Figure 1 illustrates this concept.

Table 1 presents the main technologies proposals for Smart Grid and their definitions.

In addition to the above-mentioned Smart Grid technology, a more holistic approach to energy management systems is presented in the next section. A major challenge with current systems is the limited mechanisms for coordination and communication between the management of the different parts of the system. The management of the current systems' transmission and distribution are carried out through separate activities that occur in different parts of the network [8].

\section{Energy Management Systems in Smart Grid}

The vast majority of the energy management systems just consider the monitoring and data statistics of energy consumption of consumer electronics. For these systems, manual actuation is necessary in each device to reduce energy consumption. However, the Smart Grid technologies require management systems to be smarter and able to respond to demands related to the charge control, energy management, and timing systems with micro grids [9].

Some architectural solutions for energy management systems are being integrated into a concept of Smart Grid; these are presented blow. Chang-Sci Choi develops an architecture using AMI solutions for an energy management system entitled EMM (Energy Monitoring and Management), interoperating this system with the Smart Grid. Among the

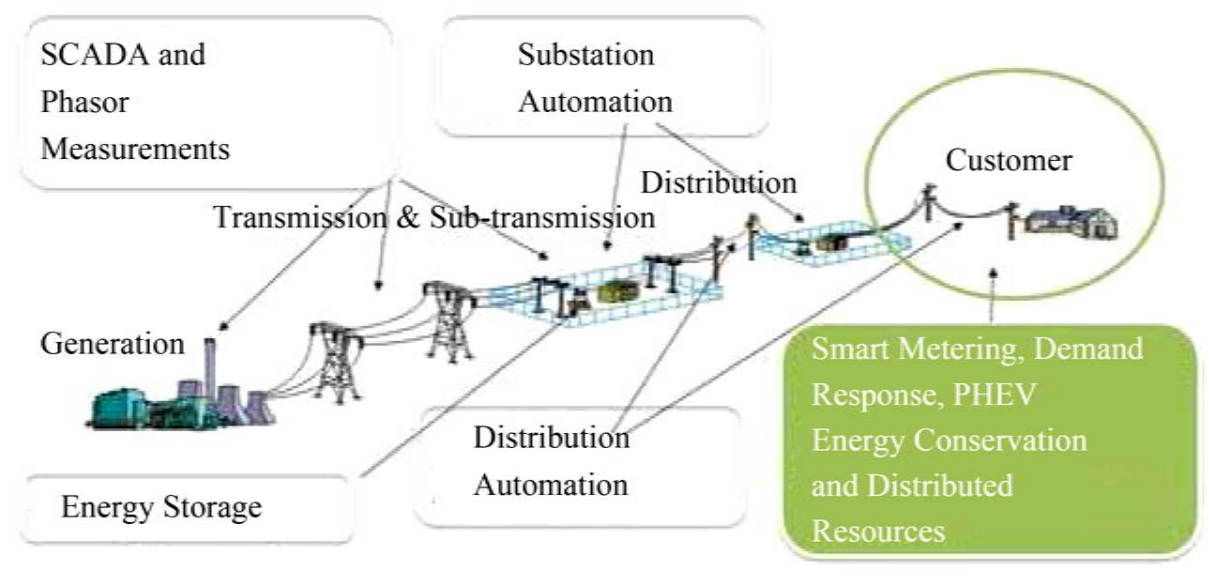

Figure 1. Concept for control and communication systems in Smart [9]. 
Table 1. Main technologies proposals for Smart Grid [7].

\begin{tabular}{|c|c|c|}
\hline Phases & Technologies & Definition \\
\hline Generation & Inverters “Grid Tie” & $\begin{array}{c}\text { Use of “Grid Tie” inverter, connecting to mains, e.g. } \\
\text { photovoltaic systems }\end{array}$ \\
\hline \multirow{3}{*}{ Transmission } & Synchrophasors & $\begin{array}{l}\text { Measurement of Synchronized Phasor, i.e. sinusoidal } \\
\text { measurements of AC magnitudes, and synchronized in } \\
\text { time expressed in phasors. To determine useful } \\
\text { information about grid performance }\end{array}$ \\
\hline & $\begin{array}{l}\text { FACTS (Flexible Alternate Current } \\
\text { Transmission Systems) para HVAC } \\
\text { (High Voltage Alternating Current) e } \\
\text { HVDC (High Voltage Direct Current) }\end{array}$ & $\begin{array}{l}\text { AC or DC (High Voltage ou Low Voltage) voltage, } \\
\text { transmission from generation to distribution }\end{array}$ \\
\hline & $\begin{array}{l}\text { Static Deviation/Compensator VAR } \\
\text { (Volt-amper reactive) }\end{array}$ & $\begin{array}{l}\text { Used for static VAR compensation, have mutual } \\
\text { inductance lines, consuming reactive power }\end{array}$ \\
\hline $\begin{array}{l}\text { Test and modeling of } \\
\text { transmission }\end{array}$ & $\begin{array}{l}\text { Software for Analysis of } \\
\text { Transmitted Power }\end{array}$ & $\begin{array}{l}\text { Full suite of tools to create, configure, customize } \\
\text { and manage power transmission systems }\end{array}$ \\
\hline $\begin{array}{l}\text { Transmission in cases of } \\
\text { distribution of HVDC and } \\
\text { generation by renewable } \\
\text { sources }\end{array}$ & Inverters and rectifiers & Used for conversion AC-DC and DC-AC \\
\hline $\begin{array}{l}\text { Transmission and } \\
\text { distribution }\end{array}$ & Substation automation & $\begin{array}{l}\text { Applications of automation: Control, timing, voltage } \\
\text { transfer, reduction and detection of loads }\end{array}$ \\
\hline $\begin{array}{l}\text { Transmission, distribution } \\
\text { and substation }\end{array}$ & Relays and circuit breakers & $\begin{array}{l}\text { The relay is actuated to detect any failure in the power } \\
\text { system, disarming the breakers of the circuits, } \\
\text { avoiding damage to the equipment }\end{array}$ \\
\hline $\begin{array}{l}\text { Distribution } \\
\text { (Distribution management } \\
\text { system-DMS) }\end{array}$ & $\begin{array}{l}\text { Fault location for } \\
\text { distribution System. }\end{array}$ & $\begin{array}{c}\text { Fault locators are devices and software, usually installed in } \\
\text { substations to identify possible fault events, calculating the } \\
\text { distance from the point of the failure to the source monitored } \\
\text { identified in distribution system }\end{array}$ \\
\hline Distribution & $\begin{array}{c}\text { AMI } \\
\text { (Advanced metering Infraestrutura) }\end{array}$ & $\begin{array}{l}\text { AMI provides the communication with the smart meters and } \\
\text { other power management devices }\end{array}$ \\
\hline $\begin{array}{l}\text { Distribution, information } \\
\text { management. }\end{array}$ & Distribution automation & $\begin{array}{c}\text { The system consists of equipment's, communication } \\
\text { infrastructure and information technology, which are } \\
\text { used as intelligence distribution system }\end{array}$ \\
\hline \multirow{4}{*}{ Information management } & $\begin{array}{l}\text { Management system of } \\
\text { measurement data }\end{array}$ & $\begin{array}{l}\text { Used for complex data collection processes measured } \\
\text { for multiple data recording technologies }\end{array}$ \\
\hline & $\begin{array}{c}\text { RTU } \\
\text { (Remote Terminal Unit) }\end{array}$ & $\begin{array}{l}\text { The function of the RTU is the remote location of the } \\
\text { system SCADA, for monitoring and control } \\
\text { of the necessary equipment }\end{array}$ \\
\hline & $\begin{array}{l}\text { SCADA } \\
\text { (Supervisory Control and } \\
\text { Data Acquisition) }\end{array}$ & $\begin{array}{l}\text { Computational system that monitors and controls } \\
\text { infrastructure and industrial plant processes based installation }\end{array}$ \\
\hline & $\begin{array}{c}\text { EMS } \\
\text { (Energy Management System) }\end{array}$ & $\begin{array}{l}\text { The EMS are tools used for operation of electrical grid, to } \\
\text { monitor, control and optimize the performance of systems } \\
\text { for generation, transmission and distribution }\end{array}$ \\
\hline $\begin{array}{l}\text { Information management } \\
\text { and consumer economics }\end{array}$ & Smart Meters & $\begin{array}{c}\text { The smart meter registers the range of the electric } \\
\text { energy consumption }\end{array}$ \\
\hline
\end{tabular}




\section{Continued}

\begin{tabular}{|c|c|c|}
\hline $\begin{array}{l}\text { Information management: } \\
\text { HAN (Home are network) } \\
\text { and LCM (Load Control } \\
\text { Modules). }\end{array}$ & $\begin{array}{c}\text { PCT } \\
\text { (Program Communication } \\
\text { Thermostat) }\end{array}$ & $\begin{array}{l}\text { Components of the control system, to detect the temperature } \\
\text { of a system, controlling the same in the desired set point. }\end{array}$ \\
\hline Residential Consumption & Load control receiver & $\begin{array}{l}\text { Are devices used for load control, directly or indirectly, } \\
\text { through voltage circuits, such as air conditioning thermostat. }\end{array}$ \\
\hline $\begin{array}{l}\text { Consumption of the } \\
\text { generation, distribution } \\
\text { and transmission }\end{array}$ & Short circuit current limiter & $\begin{array}{l}\text { Current limitation is the practice in electrical or electronic } \\
\text { circuits, the imposition of an upper limit to the current that } \\
\text { can be delivered, avoiding damage to the equipment }\end{array}$ \\
\hline $\begin{array}{l}\text { Transformers generation, } \\
\text { distribution and } \\
\text { transmission }\end{array}$ & $\begin{array}{c}\text { OLTC } \\
\text { (On-Load Tap-Changer) }\end{array}$ & $\begin{array}{c}\text { The OLTC is used to change the transformer voltage ratio, } \\
\text { without interrupting the load service }\end{array}$ \\
\hline
\end{tabular}

assumptions adopted, the most important is the division of the stream of operation and settings of residences and buildings [9].

The sizing system EMM first considered complex apartments and residential environments popular in South Korea, with advanced infrastructure of home networks and several features, such as: electricity, gas, water, and cogeneration. Figure 2 shows the architecture that is installed via the internet providing accessibility, mobility, and interoperation with other systems. Each EMM installed performs communication with smart watches "Smart Meters", and interface with networked home appliances. To report the current status of the house, the energy measurement system sends data in real time via the Internet [9].

For commercial buildings and industrial plants, the author proposes the BEMS (Building Energy Management System). However, these systems and its communication protocols depend on the market and corporate strategies at the time of construction, and its concepts of energy efficiency and energy management, which adopt generic and growing open communication standards and protocols, such as: BACnet, LonWorks, Modbus, KNX, WLAN, Zigbee, SNMP, IEC61850, DNP3, etc. To overcome these constraints, the author proposes the development of 2 CCL (Common Communication Layer) protocols. The first one is called BAS CCL, and the other one, EMM CCL. Figure 3 illustrates the configuration of EMM for heterogeneous integration BEMS in each building [9].

In both systems, the server data is analyzed by software, providing information about weather and conditions of operation of the entire plant. This information can be broadly used and incorporated into a maintenance planning, among other applications [9] [10].

Levels of data analyzed by the software can be broadly classified as:

- Level 1, Management: Supervision of computers, servers and services data management servers;

- Level 2, Automation: Smart G/W (gateway);

- Level 3, Installation: Sensors, actuators and controllers.

The software operates considering a data group, composed of service server and data management that are installed on the building control center, as illustrated in Figure 4. The Smart Gateway is installed inside the building, collecting the data of the electric power consumption through intelligent devices such as meters, sensors and actuators, etc., that are engaged in the construction of an operating system, including electricity control systems, HVAC/HVDC, lighting systems, etc. [10].

This architecture allows the system to provide multiple functions for energy saving control, such as: control of maximum demand of energy, weather-based light and dimming control by means of sensors. The information generated by the system makes it possible to provide the function of energy efficiency through predictive analysis of the trend of energy consumption, comparing with the data in real time, through a comparative analysis with similar facilities. Another option is the provision of services, such as load shifting adapting to pricing/rates through Smart Grid function; connection with renewable energy sources; and energy exchange function. In addition, it allows a selection of ideal tariff systems appropriate to the construction standard and energy consumption of the installation [10].

\section{Analysis of the Condition of Demand Response}

To meet peak demand, high-cost generating stations are required. Adding more generation was the strategy used in 


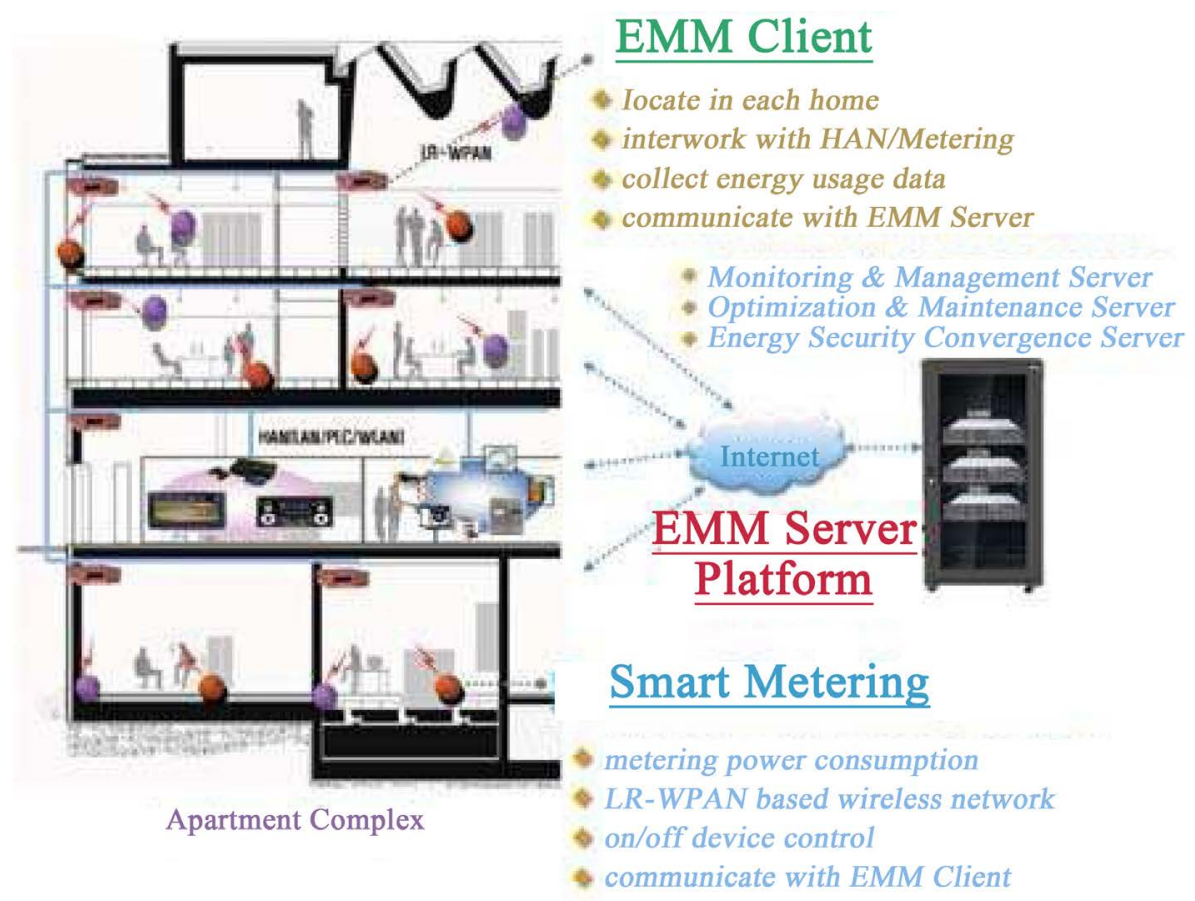

Figure 2. Systems configuration of EMM for residence [9].

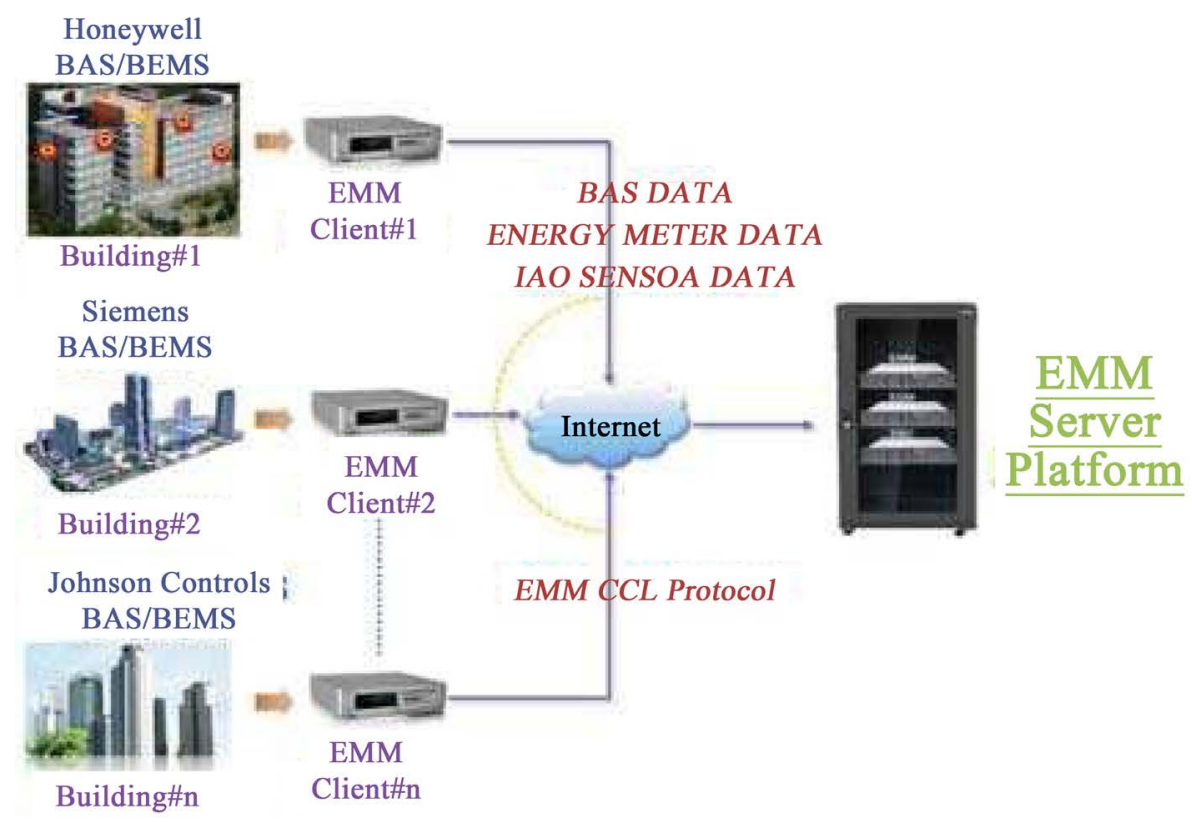

Figure 3. Systems configuration of EMM for integration with BEMS [9].

the past to meet the demand of electricity. Currently, the energy utilities have given more attention to demand management in order to reduce peak demand. Using the Smart Grid concept means more than a single technology or even a clear set of individual technologies for this [2].

Demand response (DR) is a key concept in energy demand management, which helps to reduce peak demand in critical situations. DR is defined as the changes in the use of electricity, for end consumers, of their normal consumption patterns in response to changes in the price of electrical energy over time, or the incentive payments intended to induce a better use of electricity at peak hours [11]. 


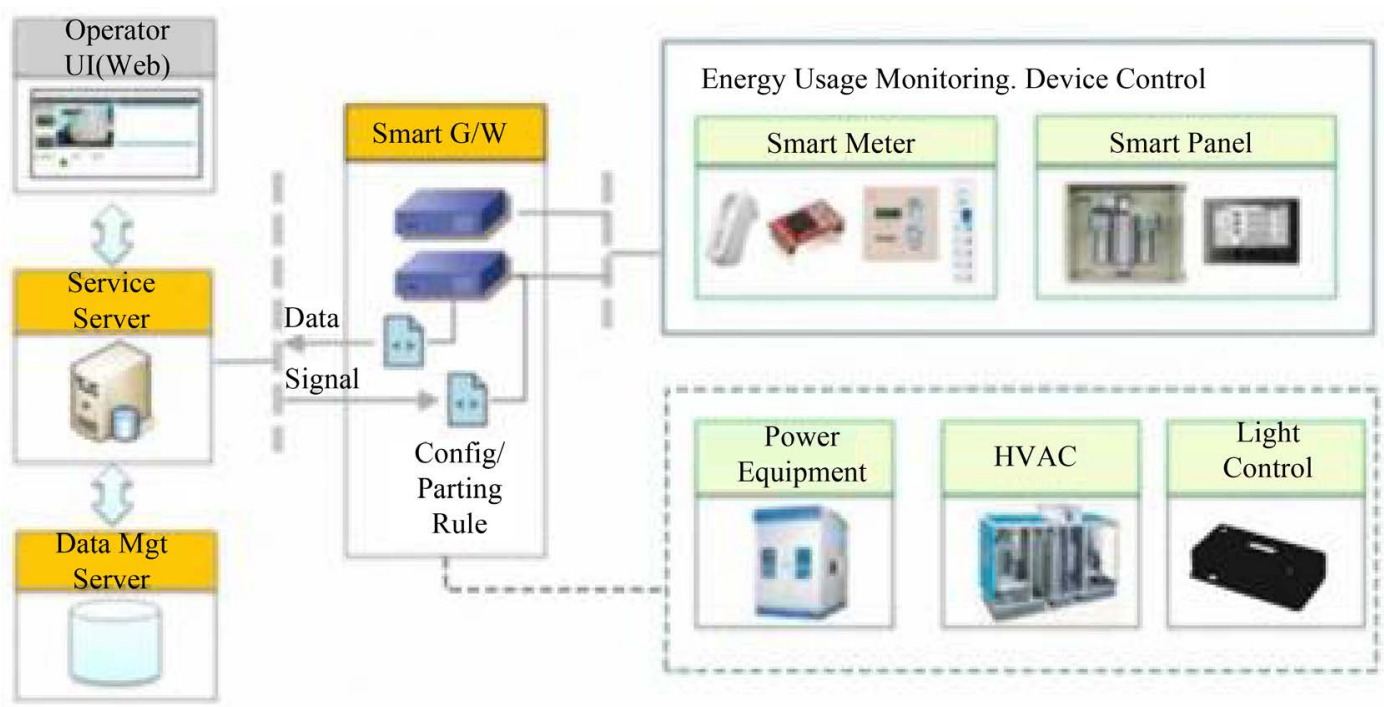

Figure 4. Performance software architecture [10].

Load management is defined as a set of objectives which aim to control directly or indirectly and/or modify patterns of electricity consumption of various consumers, aiming to reduce peak demand. This control and modification enable the supply system to meet the demand, making better use of its available generation and transmission capacity [12].

For leveling the peaks of demand, three common strategies for load management are used: "Peak Clipping”, "Load Shifting" and "Valley Filling", as illustrated in Figure 5.

"Peak Clipping": Load reduction for short peaks and periods of use, usually performed by the direct load control. In this method, the energy utilities disconnect the consumer when there is a critical situation. This direct control can be used to reduce capacity requirements, operational costs and dependence on fossil fuel generation [12].

"Valley Filling": Creation of loads during the peak period. This helps to reduce the average price of electricity. One of the methods used in industrial production, which uses the loads generated by fossil fuels [12].

"Load Shifting": Moves the peak loads for other periods of time without necessarily changing the global consumption. This method combines the benefit of "Peak Clipping" and "Valley Filling" moving existing loads during off-peak hours [12].

In programs of DR, electricity consumers play an important role in the reduction of peak demand during peak hours. Consumers can move their loads and thus help the energy utilities to prevent failures and blackouts in the electrical system, reducing the probability of stress conditions of the system. Improve energy security through the DR increases productivity and customer satisfaction. The DR also eliminates the need for high-cost generators and eventually reduces the cost of electricity [2].

In order to inform consumers with real-time data, there must be a communication link between the energy utilities and consumers. Consumers must be able to measure their electrical energy demand, in real time, in order to act for demand response events. Advanced metering infrastructure implementations (AMI) and other technologies allows the user to measure the real-time energy demand and further enhance the use of resources of DR in daily operation [13].

Therefore, it is evident that there is a need for an automatic energy management system in DR programs, which will provide more flexibility consumers.

\section{Cloud Computing Solutions in Smart Grid}

The term cloud computing has many definitions; in scenarios as Smart Grid, it is defined as a model for enabling convenient, on-demand network access to a shared pool of configurable computing resources (e.g. networks, servers, storage, applications, and services) that can be rapidly provisioned and released with minimal management effort or service provider interaction. The characteristics of cloud computing include on-demand service, 


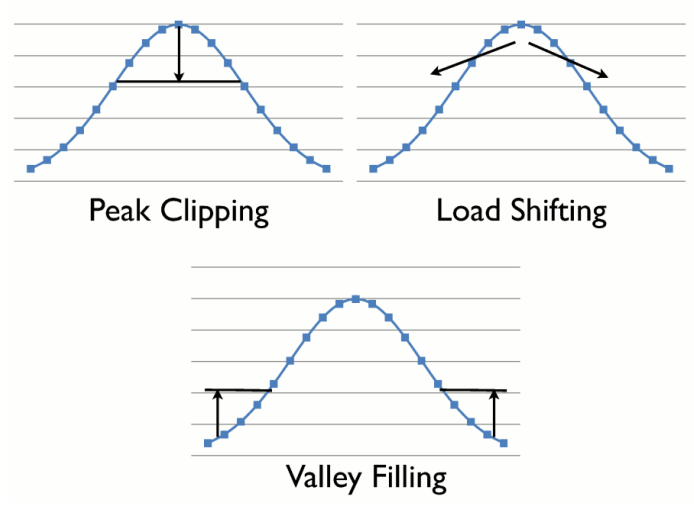

Figure 5. Strategies for load management [12].

ubiquitous network access, location independent resource pooling, rapid elasticity, and measured service.

Cloud computing is not a universal solution. It has strengths and weaknesses, and understanding them is the key to making a decision about whether it is right for a particular application [14]. The main advantages of cloud computing are: Economy of scale: sharing of computing resources between different customers; Pay per use: customers pay for the service instead of buying software licenses and hardware; On-demand usage/flexibility: cloud services can be used almost instantly and can easily be scaled up and down; External data storage: customers' data is stored externally at the location of the cloud computing provider; Highly reliable services: clouds manage themselves in case of failures or the performance degradation [15].

One of the most common applications for real-time data in manufacturing and process industries is SCADA, supervising remote processes over a network. With the growing popularity of cloud computing, many engineers and managers in the automation sector are looking at the possibility of using the cloud for SCADA. SCADA systems have evolved over time and have followed the progress of computing in general. As many view cloud computing as the next logical step in this evolution, enthusiastic visionaries foresee a fourth, "cloud" generation of SCADA, where an entire control system would be running in the cloud [16]. The cloud is creating a revolution in SCADA system architecture because it provides very high redundancy, virtually unlimited data storage, and worldwide data access all at a very low cost [17].

The cloud computing can support SCADA applications in two ways: The SCADA application is running on-site, directly connected to the control network and delivering information to the cloud where it can be stored and disseminated. The control functions of the SCADA application are entirely isolated to the control network. However, the SCADA application is connected to a service in the cloud that provides visualization, reporting, and access to remote users. These applications are commonly implemented using public cloud infrastructures (PaaS cloud service). The SCADA application is running entirely in the cloud and remotely connected to the control network. The controllers are connected via WAN links to the SCADA application running entirely in the cloud. These applications are commonly implemented using private or hybrid cloud architectures (IaaS cloud service) [18] [19].

Because of wide ranging variability of the entities in Smart Grids, there is a very high level of potential complexity in finding the optimal solution for each different Smart Grid. Smart Grid will eventually be deployed across all types of infrastructure using widespread Internet of Services, connecting all smart objects worldwide. It will become the major application domain of the Internet of Things, perhaps even referred to as the Internet of Energy [19].

\section{Barriers of Brazilian Electrical Grid}

Energy management systems in residential, commercial, and industrial sectors can play an important role in reducing peak demand of electric network. Eventually, it can help in reducing overhead and stress on transmission and distribution lines. In many countries, there are various demand response programs implemented for the industrial and commercial sector. With the installation of energy management systems, it becomes possible to perform load control, mainly through the models of RTP (Real Time Pricing) and TOU (Time-of-Use) [20].

Few demand response programs are used for management energy in the residential sector in Brazil. Direct re- 
striction of loads is the most popular method used to reduce peak demand. But by direct control of the load, the consumer comfort can be compromised. In contrast, by the method of load displacement, the loads that have less impact to the consumer lifestyle are displaced outside of peak hours, ensuring a better stability of the network.

To analyze and consider the use of the concept of demand response is important to understand the load models "Hung” on the grid, for such function Smart Grid technologies play a fundamental role. This identification in conjunction with a proper communication between the consumer and the energy utilities and demand management of domestic charges are indispensable factors for high efficiency power management systems.

\section{Final Considerations}

Energy management systems, when developed in a context Smart Grid, have their functions enhanced, in regards of the technologies making up the system. Among the main features of an energy management system, the following stand out as the most enhanced:

- Real-time performance monitoring;

- Information to compose predictive maintenance planning;

- Energy management;

- The efficiency of the power system;

- Financial economics, avoiding any sanction from the energy utilities;

- To keep the tolerance of voltage and current to the extent allowed;

- Continuous monitoring for power quality;

- Load control and management with appropriate methodology;

- To keep consumption with the limit signed;

- Database of information that can assist future decision-making;

- Identify and correct the causes of energy disorder to avoid recurrences.

Among the main Smart Grid technologies, the most important and that directly impacts the design of an energy management system are the solutions on cloud computing. Cloud computing has established itself as an adequate means to provide resources to customers, primarily in energy management systems, with access to a large amount of information and computer storage. With cloud computing, customers do not have to manage and maintain their own information technology (IT), and are not bound to its local resources which often are limited. However, for customers and energy utilities, making sure that your cloud services are usable, an appropriate level of guarantees of Quality of Service (QoS) is needed.

In recent years, the creation of solutions in Data Center Networks (DCNS) came with rapid growth in scale and complexity, making possible hosting large applications, known as cloud hosting. This growth imposes enormous challenges to update the current datacenter infrastructure, especially considering a scenario of Smart Grid with cloud computing solutions, broadly used in energy management systems.

The proliferation of the adoption of cloud computing solutions in recent years is driven by the potential for obtaining benefits such as reduced costs, greater agility, and better use of resources. However, there are many challenges to ensure the success of these cloud-based services, and these need to be understood and managed before the major use in concepts such as Smart Grid.

However, the major current infrastructures are owned by a large number of Internet Service Providers (ISPs); and it is difficult to adopt new architectures without the agreement of all parties concerned. This includes the standardization of communication protocols and creating regulations for wide use of cloud computing solutions.

\section{Acknowledgements}

The authors would like to thank the Coordenação de Aperfeiçoamento de Pessoal de Nível Superior (CAPES), the Concelho Naional de Desenvolvimento Científico e Tecnológico (CNPq), the Fundação de Amparo à Pesquisa do Estado de São Paulo (FAPESP), the Departamento de Comunicações (DECOM), the Faculdade de Engenharia Elétrica e de Computação (FEEC), and the Universidade Estadual de Campinas (UNICAMP), for their support in the development of this research.

\section{References}

[1] Eissa, M. (2012) Energy Efficiency-The Innovative Ways for Smart Energy, the Future towards Modern Utilities.

[2] Ireshika, M.A.S.T. (2014) Home Energy Management System. Universitetet I Agder, Kristiansand \& Grimstad. 
[3] Khodaei, A., Shahidehpour, M. and Bahramirad, S. (2011) SCUC with Hourly Demand Response Considering Intertemporal Load Characteristics. IEEE Transactions on Smart Grid, 2, 564-571. http://dx.doi.org/10.1109/TSG.2011.2157181

[4] Du, P. and Lu, N. (2011) Appliance Commitment for Household Load Scheduling. IEEE Transactions on Smart Grid, 2, 411-419. http://dx.doi.org/10.1109/TSG.2011.2140344

[5] Gatsis, N. and Giannakis, G.B. (2012) Residential Load Control: Distributed Scheduling and Convergence with Lost AMI Messages. IEEE Transactions on Smart Grid, 3, 770-786. http://dx.doi.org/10.1109/TSG.2011.2176518

[6] Li, J., Chung, J.Y., Xiao, J., Hong, J.W.-K. and Boutaba, R. (2011) On the Design and Implementation of a Home Energy Management System. Proceedings of the 6th International Symposium on Wireless and Pervasive Computing, Hong Kong, 23-25 February 2011, 1-6. http://dx.doi.org/10.1109/iswpc.2011.5751338

[7] Stephens, J., Wilson, E.J. and Peterson, T.R. (2015) Smart Grid (R) Evolution. Cambridge University Press, Cambridge.

[8] Jiang, T., Yu, L. and Cao, Y. (2015) Energy Management of Internet Data Centers in Smart Grid.

[9] Choi, C.-S., Ian, J.I., Park, W.-K., Jeong, Y.-K. and Lee, I.-W. (2011) Proactive Energy Management System Architecture Interworing with Smart Grid. Proceedings of the IEEE 15th International Symposium on Consumer Electronics, Singapore, 14-17 June 2011, 1-4.

[10] Park, K., Kim, Y., Kim, S., Kim, K., Lee, W. and Park, H. (2011) Building Energy Management System based on Smart Grid. Proceedings of the IEEE 33rd International Telecommunications Energy Conference, Amsterdam, 9-13 October 2011, 1-4.

[11] Balijepalli, V.S.K.M., Pradhan, V., Khaparde, S.A. and Shereef, R.M. (2011) Review of Demand Response under Smart Grid Paradigm. Proceedings of the 2011 IEEE PES International Conference on Innovative Smart Grid Technologies-India, Kollam, 1-3 December 2011, 236-243. http://dx.doi.org/10.1109/iset-india.2011.6145388

[12] Paracha, Z.J. and Doulai, P. (1998) Load Management: Techniques and Methods in Electric Power System. Proceedings of the International Conference on Energy Management and Power Delivery, Singapore, 3-5 March 1998, 213217.

[13] Medina, J., Muller, N. and Roytelman, I. (2010) Demand Response and Distribution Grid Operations: Opportunities and Challenges. IEEE Transactions on Smart Grid, 1, 193-198. http://dx.doi.org/10.1109/TSG.2010.2050156

[14] Bashir, A.K., Ohsita, Y. and Murata, M. (2015) Abstraction Layer Based Distributed Architecture for Virtualized Data Centers. Proceedings of the Sixth International Conference on Cloud Computing, GRIDs, and Virtualization, Nice, 22-27 March 2015, 62-67.

[15] Frey, S., Disch, S., Reich, C., Knahl, M. and Clarke, N. (2015) Cloud Storage Prediction with Neural Networks. Proceedings of the Sixth International Conference on Cloud Computing, GRIDs, and Virtualization, Nice, 22-27 March 2015, 68-72.

[16] Mcilvride, B. (2012) Will SCADA Envolve to the Cloud? http://real-timecloud.com/

[17] Combs, L. (2011) Cloud Computing for SCADA. http://www.controleng.com/single-ar

[18] Conway, G., Carcary, M. and Doherty, E. (2015) A Conceptual Framework to Implement and Manage a Cloud Computing Environment. Proceedings of the Sixth International Conference on Cloud Computing, GRIDs, and Virtualization, Nice, 22-27 March 2015, 138-142.

[19] Markovic, D.S., Zivkovic, D., Branovic, I., Popovic, R. and Cvetkovic, D. (2013) Smart Power Grid and Cloud Computing. Renewable \& Sustainable Energy Reviews, 24, 566-577. http://dx.doi.org/10.1016/j.rser.2013.03.068

[20] Albadi, M.H. and El-Saadany, E.F. (2007) Demand Response in Electricity Markets: An Overview. Proceedings of the 2007 IEEE Power Engineering Society General Meeting, Tampa, 24-28 June 2007, 1-5. 